\title{
Applications of Nanotechnology in Bladder Cancer Therapy
}

\author{
Jong-Wei Hsu, PhD. and Michael R. King*, PhD. \\ Department of Biomedical Engineering, Cornell University, Ithaca, New York, USA
}

Submitted June 2012. Accepted for publication September 2012.

\begin{abstract}
Effective therapies can prevent superficial bladder cancer from developing into muscle-invasive stage or more severe stages which require radical cystectomy and negatively affect life quality. In terms of therapeutic approaches against superficial bladder cancer, intravesical (regional) therapy has several advantages over oral (systemic) therapy. Though urologists can directly deliver drugs to bladder lesions by intravesical instillation after transurethral resection, the efficacy of conventional drug delivery is usually low due to the bladder permeability barrier and bladder periodical discharge. Nanoparticles have been well developed as pharmaceutical carriers. By their versatile properties, nanoparticles can greatly improve the interactions between urothelium and drugs and also enhance the penetration of drugs into urothelium with lesions, which dramatically improves therapeutic efficacy. In this review, we discuss the advances of nanotechnology in bladder cancer therapy by different types of nanoparticles with different encapsulating materials.
\end{abstract}

Keywords: bladder cancer, nanoparticle, liposome, intravesical

\section{INTRODUCTION}

Bladder cancer is the fourth most common cancer in American men, and is estimated to be diagnosed in 73,510 people and to cause 14,880 deaths in the US in 2012 [1]. Bladder cancer is also the cancer which has the highest cost from diagnosis to death per person and is the fifth most expensive cancer to treat overall [2]. However, the cost of treatments associated with bladder cancer is not proportionate to the incidence of bladder cancer, which implies that the efficacy of follow-up therapies needs to be greatly improved. About $70 \%$ of bladder cancer patients are initially diagnosed as in superficial stage [3], and receive transurethral resection (TUR) to remove superficial tumors followed by intravesical chemotherapeutics, such as mitomycin $\mathrm{C}$, adriamycin, and bacille CalmetteGuérin (BCG) to eradicate residual cancer cells. However, 50-70\% of superficial lesions recur and about 10-30\% develop into muscle-invasive tumors [3-5]. The standard

*Corresponding author: Michael R. King, 526 Campus Road, 205 Weill Hall, Ithaca, NY 14853. Phone: (607) 255-9803. E-mail: mike.king@cornell.edu. First author E-mail: jh967@cornell.edu. 
treatment for muscle-invasive bladder cancer is radical cystectomy which can cause loss of urinary or sexual functions [6]. Therefore, effective therapeutic approaches against superficial bladder cancer are greatly needed to ensure patients' quality of life.

Since most bladder cancers are superficial, a cancerous bladder is an ideal organ for regional therapy. High grade superficial tumors are visible by cystoscopy and can be removed by electrocautery without invasive surgery. Drugs can be delivered to the bladder lesions through intravesical instillation without specific homing concerns. Moreover, the contact of drugs with bladder lesions does not go through the circulatory system, hence higher dosage of drugs can be loaded without inducing severe systemic side effects to other organs. The luminal side of the urothelium develops numerous rigid-looking plaques which cover the urothelial surface. The outer leaflet of these plaques is twice as thick as the inner leaflet. Therefore, this layer of specialized plaques is termed the asymmetric unit membrane. The specialized asymmetric unit membrane on top of the urothelium forms a barrier and only allows less than $5 \%$ of the drug dose to be absorbed into the circulation system [7-9], thus ensuring the dominance of intravesical treatment in bladder cancer therapy.

Nanoparticles have been well developed and applied as pharmaceutical carriers in cancer therapies due to their versatile capabilities, such as carrying various drugs, protecting drug from degradation, promoting interaction between drugs and target cells, or enhancing permeability of drugs [10-12]. These advantages can address the weaknesses of conventional intravesical drug delivery. Scientists have developed variant types of nanoparticles as drug carriers for intravesical therapy and have achieved positive results in preclinical studies. In this review, we first introduce the structure of the bladder urothelium and bladder permeability barrier. The second part introduces the bladder diseases, including bladder cancers and painful bladder syndrome (PBS). The third part summarizes the applications of different nanoparticles in intravesical therapy. Finally, perspectives for nanotechnology in bladder cancer therapy are discussed.

\section{BLADDER STRUCTURE AND BARRIER}

\subsection{Bladder Structure}

The bladder is a hollow organ which stores urine secreted from the kidneys. The lumen capacity of bladder is about $400-600 \mathrm{~mL}$. When the urine amount reaches about $150-300 \mathrm{~mL}$, an urge to urinate is induced [13]. The bladder wall is elastic and impermeable, allowing the bladder to store urine for a short term while preventing urine and contained waste substances from penetrating through the bladder wall. The bladder wall is composed of multiple layers of tissue. The layers from outside to inside are: adventitia, detrusor muscle, submucosa, and mucosa which consists of lamina propria and transitional epithelium (urothelium). The urothelium is the first lining layer within the bladder lumen and serves as a bladder permeability barrier [14]. The urothelium is composed of three different cells: basal cells, intermediate cells, and umbrella cells (listed from outside to inside) [15]. These three cell types differ in their distinct morphologies [16]. Basal cells have diameters of 5-10 $\mu \mathrm{m}$ and fuse to form intermediate cells with a diameter of $20 \mu \mathrm{m}$. The intermediate cells further fuse to form umbrella cells with diameters of 50-120 $\mu \mathrm{m}$, depending on the degree of bladder stretch [17]. 


\subsection{Bladder Permeability Barrier}

Umbrella cells have two remarkable morphological features that differ from basal and intermediate cells [15]. First, they have scalloped-shape plaques covering the apical membrane, which makes the outer leaflet of the apical membrane thicker than the inner leaflet and forms the asymmetric unit membrane [18]. Second, umbrella cells have many cytoplastic vesicles which are associated with cytoskeletal fibrils [19]. Each plaque above the umbrella cell membrane has about 1000 subunits and are composed of four uroplakins, UPIa (27 kDa), UPIb (28 kDa), UPII (15 kDa), and UPIII (47 kDa) [20]. Each subunit is arranged hexagonally with an inner loop composed of six large particles (UPIa or UPIb) and an outer loop composed of six small particles (UPII or UPIII) $[13,15,21]$. The barrier function of umbrella cells is established by the tight arrangement of these scalloped-shape plaques and further enhanced by a mucin layer on the luminal side. This mucin layer is composed of glycosaminoglycans (GAGs), which are hydrophilic and form an aqueous layer upon umbrella cells. Therefore, this GAG layer can prevent urine substances from adhering to the bladder lumen [22].

\section{BLADDER CANCER AND DISEASE}

\subsection{Bladder Cancer}

Over $90 \%$ of bladder cancers (BCa) are derived from bladder urothelial cells; i.e., urothelial carcinoma. Other BCa types are squamous cell carcinoma (originated from squamous cells as a result of chronic bladder inflammation) and adenocarcinoma (originated from the cells which make up glands).

Many factors are associated with bladder cancer incidence. First, smoking is the most potent factor to cause bladder cancer [23, 24]. Certain chemicals in cigarettes have been identified to be associated with bladder cancer [25]. Second, exposures to some carcinogens in the work place, such as benzidine or aromatic amines, also contribute to bladder cancer. Occupations at high risk of bladder cancer are bus drivers, rubber workers, motor mechanics, leather workers, blacksmiths, machine setters and mechanics [26]. Third, salted and barbecued meats may also be associated with bladder tumorigenesis, since those foods contain carcinogens such as $\mathrm{N}$-nitroso compounds and heterocyclic amines [27].

The diagnosis of bladder cancer is determined by a positive cytology, cystoscopy and biopsy. Common symptoms of bladder cancer include painless gross hematuria (the presence of red blood cells in the urine), urinary frequency, bladder irritability, urgency, and dysuria. Bladder cancer staging is classified by the location and spread of tumors (Figure 1).

According to the American Joint Committee on Cancer (AJCC) TNM staging system, tumor staging is described as below. TX: Main tumor cannot be assessed due to lack of information. T0: No evidence of a primary tumor. Ta: Non-invasive papillary carcinoma. Tis: Non-invasive flat carcinoma. T1: The tumor has grown from the urothelial layer into the connective tissue below. T2: The tumor has grown into the muscle layer. T3: The tumor has grown through the muscle layer and into the fatty tissue. T4: The tumor has spread beyond the fatty tissue and into adjacent organs or tissues. Among all stages of bladder cancer, only non-muscle invasive cancers (Ta, Tis, and T1) are suitable for intravesical therapy. 


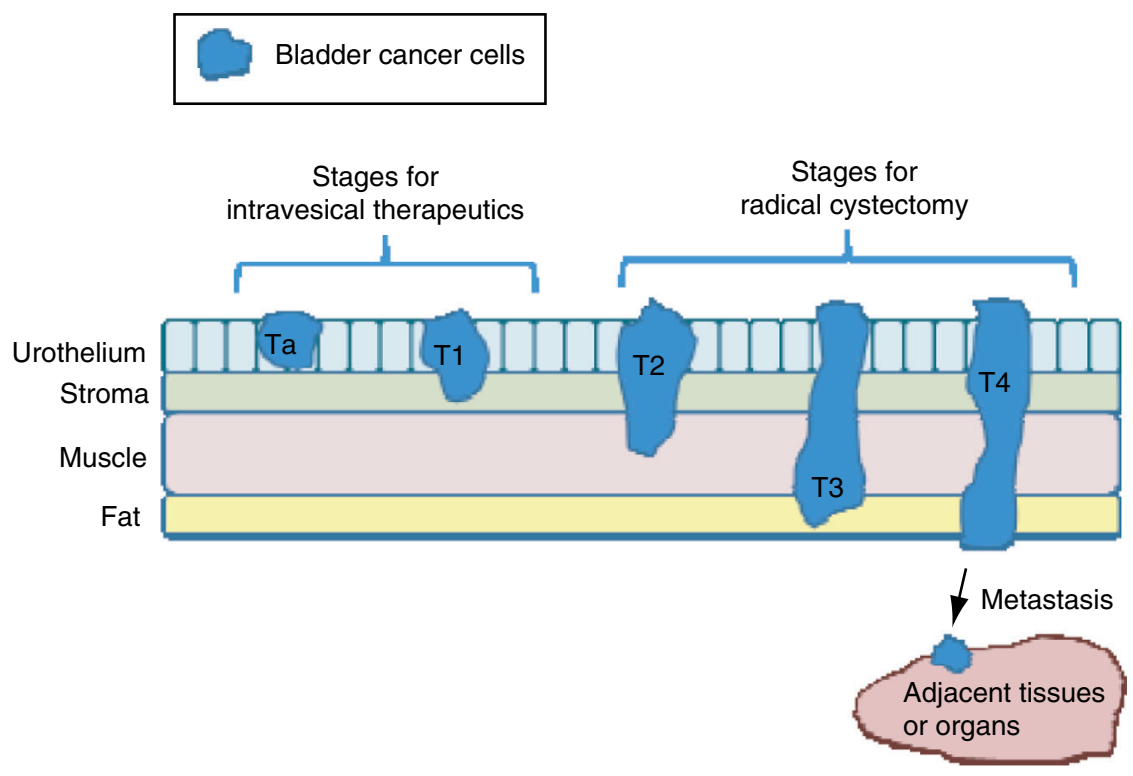

Figure 1. The staging of bladder cancer and therapeutic treatments. The staging of bladder cancer is based on the location and spread of bladder cancer cells. Ta: Non-invasive papillary carcinoma; T1: The tumor has grown from urothelial layer into connective tissue (stroma); T2: The tumor has grown into the muscle layer; T3: The tumor has grown through the muscle layer and into the fatty tissue; T4: The tumor has spread beyond the fatty tissue and into adjacent organs or tissues. For Ta or T1 stage of bladder cancer, patients receive transurethral resection to remove superficial tumors followed by intravesical therapeutics. For T2, T3, and T4 stages of bladder cancer, radical cystectomy is the standard treatment for the patients.

\subsection{Painful Bladder Syndrome (PBS)}

Painful bladder syndrome (PBS), also known as interstitial cystitis, is a condition of chronic bladder pain with syndromes of irritation, nocturia, urgency, and frequency [28-31], while other abnormal bladder conditions have been excluded. PBS is a debilitating and chronic disease which causes negative impact on life quality of patients [32]. PBS can result from various urological abnormalities, such as endometriosis or bladder cancer [33-38]. Since the etiology of PBS remains incompletely understood, all of the proposed therapeutic approaches are based on empirical evidence [32]. Factors that contribute to PBS include infection, allergic reaction, autoimmune response, neurogenic inflammation, urothelial dysfunction, and genetic factors [39, 40]. Many studies have indicated that the symptoms of PBS are derived from inflammation in the bladder [41]. Animal studies of PBS further showed that the accumulation of neutrophils in the bladder wall induces a high level of inflammatory cytokines and further activates some inflammatory gene expression [42, 43]. 


\section{LIPOSOMES AND NANOPARTICLES IN INTRAVESICAL THERAPY \\ 4.1. Liposomes}

Liposomes are artificially-synthesized phospholipid vesicles with bilayer membrane structure, which were first developed by Alec Bangham in 1961 [44]. Not just limited to biophysical research, liposomes have been developed and applied in carrying different molecules such as drug molecules, nucleotides, protein, and plasmids. The binding of liposomes to human bladder urothelial cancer cell lines potentiates the application of liposomes in bladder cancer therapy [13]. Johnson et al. [45] found that negatively charged large multilamellar vesicles (MLVs) show improved binding to four different human bladder tumor cell lines (253J, J82, T24, TCCSUP) compared to small sonicated vesicles or vesicles consisting of uncharged phosphatidylcholine (PC). Furthermore, MLV specifically bind to tumor cells but not to normal fetal bladder cells. These data suggest that liposomes may be ideal pharmaceutical carriers for intravesical therapy against bladder cancer.

Overexpression of oncogenes in the urothelium is one of the major causes of urothelial carcinoma induction [46]. Therefore, silencing of the activated oncogenes via small interfering RNA (siRNA) can be an effective approach to suppress cancer growth. Polo-like kinase-1 (PLK-1) is one of the regulators of mitotic progression in mammalian cells [47], which has been associated with the development of variant cancers [48-51]. Nogawa et al. [52] first reported that PLK-1 is associated with grades of bladder cancer and the survival rate of bladder cancer patients. By intravesically instilling a complex of PLK-1 siRNA and liposomes into the mouse bladder with an orthotopic tumor, Nogawa et al. successfully transfected PLK-1 siRNA into cancer cells and reduced PLK1 expression, resulting in suppression of cancer growth in this mouse model. However, the effect of liposomes alone was not investigated [52]. This was the first study showing the suppression of bladder cancer growth by intravesical delivery of siRNA/liposomes in a mouse model. Seth et al. [53] further used PLK-1 siRNA/liposomes to suppress orthotopic bladder cancer growth in a mouse model. Besides the successes in mouse models, Arum et al. [54] showed that intravesical delivery of siRNA/liposomes can successfully transfect siRNA into urothelium in a rat model.

Intravesical administration of anti-proliferative agents is one of the current therapeutic approaches against bladder cancer. Liposomes encapsulated with cytotoxic agents have been shown to improve the efficacy of intravesical therapy. Killion et al. [55] first demonstrated that recombinant human interferon alpha (IFN- $\alpha$ ) encapsulated in liposomes achieves significantly greater cell growth inhibition on bladder cancer cell line 253J than free IFN- $\alpha$ alone or liposomes with saline. Interestingly, the same study also found that a subline of $253 \mathrm{~J}$, originally resistant to free IFN- $\alpha$, became sensitive to IFN- $\alpha$ encapsulated in liposomes. Frangos et al. [56] further demonstrated that intravesical administration of radiolabeled IFN- $\alpha$ or radiolabeled liposomes did not spread to distant organs.

The encapsulation of small peptides in liposomes is an alternative approach against bladder cancer. Dinney et al. [57] showed that intravesical administration of encapsulated synthetic lipophilic muramyl tripeptide phosphatidylethanolamine (MTP-PE) can effectively eradicate orthotopically implanted human transitional cell carcinoma cells $(253 \mathrm{~J}-\mathrm{V})$ in athymic nude mice. After treatment of liposome/MTP-PE, 
activated macrophages were found in the bladders of mice but not in the bladders of control mice not treated with liposome/MTP-PE. In the same study, in vitro data showed liposome/MTP-PE increased the cytotoxicity of macrophages against $253 \mathrm{~J}-\mathrm{V}$ cells.

Intravesical administration of plasmid-containing liposomes is also feasible in bladder cancer therapy. Many studies have demonstrated that transfection of some cytokine genes, such as IL-2 [58, 59], IL-4 [60], IL-12 [61], interferon-gamma [62], and granulocytemacrophage colony-stimulating factor [63], into tumor cells can induce antitumor immune responses and cause growth suppression of pre-established tumors in animals. Horiguchi et al. [64] demonstrated that intravesical instillation of plasmid (IL-2) encapsulated in cationic liposomes can sufficiently transfect IL-2 gene into orthotopically established murine bladder tumors and further eradicate tumors and increase animal survival rate compared to control. This study of in situ intravesical IL-2-liposome delivery was one of the first to suggest this direction of immunotherapy against bladder cancer.

Conjugation of specific proteins to liposomes can promote the tumor-selective accumulation of liposomes. Transferrin receptor is overexpressed in bladder transitional cell carcinoma and little expressed in normal urothelium [65]. Derycke et al. [66] showed that conjugation of transferrin to liposomes can deliver encapsulated photosensitizer mainly into bladder tumoral tissue and little into normal urothelium and stromal tissue, suggesting that transferrin-conjugated liposome could be a promising tool for tumoral selective therapy for superficial bladder cancer.

Besides serving as pharmaceutical carriers, liposomes alone can directly contribute to bladder disease therapy. PBS has been associated with dysfunction or leaky urothelium. Therefore, improving the urothelial barrier function could be one therapeutic goal. Fraser et al. [67] demonstrated that intravesical instillation of liposomes could enhance barrier function of a chemical-induced dysfunctional urothelium and also increase resistance to irritant penetration in a rat model. Tyagi et al. [68] further showed that intravesical administration of empty liposomes of uncharged zwitterionic phospholipids, but not cationic or anionic phospholipids, can reduce protamine sulphate (PS) induced irritation and also decrease PS induced bladder contraction frequency in a rat model. Moreover, intravesical liposomes with botulinum toxin and tacrolimus have been investigated in a preclinical study on overactive bladder, and inflammatory cystitis [69, 70]. In a clinical study, Chuang et al. [71] demonstrated that intravesical liposomes show similar therapeutic efficacy as oral pentosan polysulfate sodium, which is approved by the U.S. Food \& Drug Administration for the treatment of PBS. Lee et al. [72] also indicated that intravesical liposomes can improve the pain score of patients with PBS and do not cause any unanticipated adverse effect.

\subsection{Protein Nanoparticles}

Protein nanoparticles are composed of biological components and hence have biocompatible, biodegradable, non-antigenic properties, and are easily amenable to particle surface modification and covalent attachment of drugs [13, 73]. While protein nanoparticles have been employed as pharmaceutical carriers in multiple cancer therapies [74, 75], blood protein albumin has attracted most of the attention as a pharmaceutical carrier and has also been well characterized in bladder cancer studies. 
Mckiernan et al. [76] demonstrated that intravesical nanoparticle albumin-bound paclitaxel (Abraxane $\left.{ }^{\circledR}, \mathrm{ABI}-007\right)$ has higher solubility and lower toxicity than docetaxel in systemic therapy, and can achieve the maximum deliverable dose while limiting cytotoxicity in clinical applications. In the intravesical therapy, commercial paclitaxel contains Cremophor which causes some micelle formation and interferes with paclitaxel's transportation across the urothelium. To improve the delivery efficiency of paclitaxel in intravesical therapy against bladder cancer, Lu et al. [77] developed a paclitaxel-loaded gelatin protein nanoparticle for intravesical therapy. Using a canine model, they showed that an intravesical dose of paclitaxel-loaded protein nanoparticles can release 2.6-fold higher drug concentration than Cremophorformulated paclitaxel in the urothelium and lamina propria tissue layers. Therefore, gelatin-based protein nanoparticles can provide a more extensive delivery for intravesical therapy. For the application of protein nanoparticles in clinical study, in a phase I clinical trial, nanoparticle albumin-bound paclitaxel was applied in intravesical therapy for BCG refractory non-muscle invasive bladder cancer [76], and exhibited minimal toxicity and systemic absorption in patients.

\subsection{Polymeric Nanoparticles}

Polymeric nanoparticles have multiple advantages in terms of biocompatability, drug release, size control, and low toxicity [78]. Some of the most commonly used polymers for nanoparticles are poly(lactide-coglycolide), poly(lactic acid), poly( $\varepsilon$-caprolactone), chitosan, and poly(alkylcyanoacrylates) [79]. Polymeric nanoparticles are most attractive in that there exist a large number of materials for nanoparticle synthesis. Different compositions of polymeric nanoparticles can be applied to encapsulate various drugs and deliver them to specific cellular surfaces. Application of polymeric nanoparticles in intravesical therapy has several advantages, such as increasing the retention time of drugs in the bladder, keeping higher local drug concentration, and reducing drug loss during urine discharge. Chitosan is a degradable, nontoxic, and natural polysaccharide isolated from the exoskeleton of crustaceans, and has been widely used as a biomaterial in humans [80-83]. Chitosan has three key properties that can improve intravesical delivery of drugs [84]. First, the polycationic charge and mucosadhesive property of chitosan promote adhesion to the negatively-charged bladder surface and hence increase the retention time of drug. Second, the high viscosity of chitosan solution protects itself from urine discharge. Third, chitosan can loosen gap junctions and enhance urothelial permeability [85]. Indeed, Ghosn et al. [86] reported that an imidazole-functionalized conjugate of polysaccharide chitosan (chitosan-IAA) can enhance the mucosal permeability and facilitate transepithelial delivery of optical contrast agents.

Modification of chitosan-based polymeric nanoparticles can also achieve improved encapsulation of drug and selective incorporation into bladder cancer cells. Bilensoy et al. [87] compared the delivery efficiency of the intravesical chemotherapeutic agent Mitomycin C (MMC) with three cationic nanoparticles of chitosan (CS), poly-epsiloncaprolactone coated with chitosan (CS-PCL), and poly-epsilon-caprolactone coated with poly-L-lysine (PLL-PCL). Their results showed that CS-PCL exhibited complete 
drug release and was the most efficient formulation to encapsulate fluorescent markers. Most importantly, CS-PCL nanoparticles and MMC share hydrophilic properties; hence CS-PCL with a fluorescent marker were selectively incorporated into bladder cancer cells, but not by normal bladder cells.

\subsection{Lipid Nanoparticles}

There are two lipid nanoparticle systems that have been applied to cancer therapy, solid lipid nanoparticles (SLNs) and nanostructured lipid carriers (NLCs), both composed of lipid instead of phospholipid. SLNs have attracted interest in drug delivery by their specific advantages, such as stable structure, protection of labile drugs from degradation, controlled drug release, and specific targeting [88]. Furthermore, SLNs can encapsulate various drugs with diverse physicochemical properties [89-93]. However, the low drug loading of SLNs limits the control of drug release and undesirable drug expulsion during storage [94]. NLCs have been developed as the second generation of SLNs, which are composed of both solid and liquid lipids and hold the same advantages as SLNs. Importantly, NLCs show higher drug loading and less drug expulsion during storage [95]. To date, lipid nanoparticles have been applied to preclinical intravesical therapy. Kang et al. [96] showed that intravesical instillation of lipid nanoparticles which encapsulate p21-inducible double-stranded RNA can successfully deliver doublestranded RNA into tumoral tissue and induce $\mathrm{p} 21$ protein expression to further extend the survival of mice with established orthotopic bladder cancer. With the excellent properties of high drug loading and high tolerability, lipid nanoparticles may prove to be excellent pharmaceutical carriers in intravesical therapy against bladder diseases.

There are several important differences between these lipid nanoparticles and liposomes. (1) Structure: Lipid nanoparticles are vesicles with a single layer of lipid while liposomes are vesicles with two layers of lipid. (2) Composition: Lipid nanoparticles are composed of solid lipids (solid at room temperature) while liposomes are composed of phospholipids. (3) Drug leakage: Lipid nanoparticles show little drug leakage due to the solid matrix while liposomes can exhibit significant drug leakage. (4) Hydrolysis: Lipid nanoparticles are stable against hydrolysis of drug while liposomes are not. (5) Storage stability: Lipid nanoparticles are more stable than liposomes during storage [97].

\subsection{Magnetically Responsive Nanoparticles}

Magnetically responsive nanoparticles have been developed recently as novel drug vectors for cancer therapy and for diagnostic imaging $[98,99]$. This type of nanoparticle is composed of magnetic elements such as iron, nickel, or cobalt, or chemical compounds. Magnetic nanoparticles can be directed and localized to specific tumor regions by administration of a magnetic field [100]. Magnetic nanoparticles with metallic cores can be coated with organic or inorganic shells to optimize the delivery of drugs to specific cell surfaces [13]. Doxorubicin is one chemotherapeutic reagent for intravesical treatment for bladder cancer [101] and it has also been well studied for drug delivery using magnetic targeted carriers [102]. Leakakos et al. [103] first demonstrated that magnetic nanoparticles with doxorubicin can be targeted and retained in specific regions of the bladder by administrating a magnetic field. In their study, the magnetic 
nanoparticles were composed of metallic iron and activated carbon. Doxorubicin was absorbed into the activated carbon and iron core functions for magnetic susceptibility. This study demonstrated the feasibility to apply magnetic nanoparticles as pharmaceutical carriers in intravesical therapies.

\section{DISCUSSION AND FUTURE PERSPECTIVES}

Intravesical therapy is an adjuvant treatment after transurethral resection for superficial bladder cancer, while systemic therapy is typically for muscle-invasive or metastatic bladder cancer [104]. Figure 2 summarizes applications of various types of liposomes/nanoparticles as pharmaceutical carriers in the intravesical therapy against bladder diseases including superficial bladder cancer and PBS. New generations of intravesical treatments utilizing nanotechnology may not only advance the penetration of drugs but also deliver encapsulated molecules which cannot be absorbed by the urothelium. Most importantly, based on limited clinical studies [72, 76], these advances with nanotechnology may come without obvious side effects. By exploiting the versatile characteristics of nanoparticles, intravesical therapy efficacy can be improved in several directions. First, nanoparticles can be very beneficial to BCG therapy. Intravesical BCG is still the most efficient therapy against superficial bladder cancer

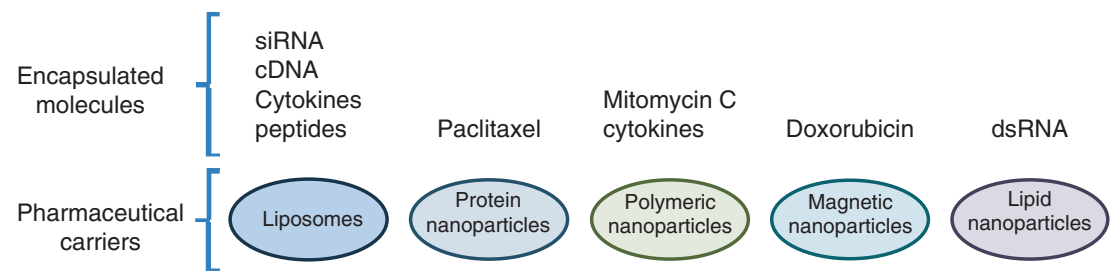

Figure 2. Applications of liposomes/nanoparticles as pharmaceutical carriers in the intravesical therapy against bladder cancer. Variant liposomes can encapsulate small interfering RNA (siRNA), complementary DNA (cDNA), cytokines, or small peptides and be applied in intravesical therapy against bladder cancer. Many drugs against bladder cancer can also be encapsulated in different types of nanoparticles for intravesical treatments. Paclitaxel is a mitotic inhibitor used in cancer therapy, which can be encapsulated in protein nanoparticles. Mitomycin $\mathrm{C}$ is a conventional drug for bladder cancer, which can be loaded in polymeric nanoparticles to improve its therapeutic efficacy. Cytokine IL-12 can eradicate bladder cancer cells, which can be also encapsulated in polymeric nanoparticles for intravesical treatment. Doxorubicin is a drug widely used in many cancers, which can be loaded in magnetic nanoparticles for intravesical therapy against bladder cancer. p21inducible double-stranded RNA can induce $\mathrm{p} 21$ protein expression which activates cell cycle arrest and apoptosis, and further extend the survival of mice with established orthotopic bladder cancer. 
after TUR. Many positive and negative factors have been associated with the poor response of BCG therapy [105]. Activating or silencing these key genes involved in BCG-induced immune responses by using nanotechnology approaches is feasible to improve the BCG therapeutic efficacy. Second, PBS is still a mystery of bladder disease due to its unknown cause. Since many reports supported that liposomes could be an ideal solution against PBS, the customized liposomes could be designed based on individual symptoms and reach a better therapeutic result.

Nanoparticles have limitations, nevertheless. The toxicity of nanoparticles is indeed a concern during systemic therapy. However, little evidence can be found that intravesical nanoparticles/liposomes do or do not cause toxicity or side effects in animals or human patients. The reason may be that intravesical nanoparticles/liposomes do not directly contact the circulatory system. We still cannot exclude the possibility of toxicity induced by overdose of intravesical nanoparticles/liposomes, and more intravesical nanoparticle experiments are required for confirmation of their safety in humans.

\section{CONCLUSIONS}

Intravesical drug delivery is a preferred therapeutic approach against superficial bladder cancer due to several advantages over oral therapy, such as direct administration of drug on bladder lesions and reduced systemic side effects. However, intravesical therapy also has limited therapeutic efficiency due to factors such as bladder permeability barrier and bladder periodical discharge. Fortunately, the development of nanoparticles as pharmaceutical carriers in intravesical therapy overcomes the disadvantages of conventional intravesical therapy. Various types of nanoparticles have been well associated with bladder disease therapies, including superficial bladder cancer and PBS. Limited evidence mostly from animal studies supports that applications of nanotechnology in intravesical therapy may enhance the retention of drug in the bladder and drug permeability into bladder lesions. Furthermore, nanoparticles can carry some molecules which cannot actively transport into bladder lesions, such as small interfering RNA. Those outstanding strengths determine the dominant roles of nanoparticles in the next generation of intravesical therapy against bladder diseases. However, to reduce the risk of distant metastasis, the standard treatment for muscle-invasive bladder cancer is radical cystectomy instead of regional or systemic drug therapy. Therefore, the application of nanotechnology for bladder cancer is still focused on non-muscle invasive bladder cancer. Developing a better nanoparticle system which can deliver intact drugs/molecules to bladder urothelium without severe side effects is a goal for future therapy against bladder diseases.

\section{ACKNOWLEDGEMENTS}

The current work was supported by the Cornell Center on the Microenvironment \& Metastasis through Award Number U54CA143876 from the National Cancer Institute of the National Institutes of Health. The content is solely the responsibility of the authors and does not necessarily represent the official views of the National Cancer 
Institute or the National Institutes of Health. The authors thank Ms. Yue Geng for editing this article.

\section{CONFLICT OF INTEREST}

The authors indicated no potential conflicts of interest.

\section{REFERENCES}

[1] Siegel R, Naishadham D, Jemal A. Cancer statistics, 2012. CA Cancer J Clin. 2012, 62(1):10-29.

[2] Hong YM, Loughlin KR. Economic impact of tumor markers in bladder cancer surveillance. Urology. 2008, 71(1):131-5.

[3] Gee J, Sabichi AL, Grossman HB. Chemoprevention of superficial bladder cancer. Critical reviews in oncology/hematology. 2002, 43(3):277-86.

[4] Cookson MS, Herr HW, Zhang ZF, Soloway S, Sogani PC, Fair WR. The treated natural history of high risk superficial bladder cancer: 15-year outcome. The Journal of urology. 1997, 158(1):62-7.

[5] Schenk-Braat EA, Bangma CH. Immunotherapy for superficial bladder cancer. Cancer immunology, immunotherapy : CII. 2005, 54(5):414-23.

[6] El-Bahnasawy MS, Osman Y, El-Hefnawy A, Hafez A, Abdel-Latif M, Mosbah A, Ali-Eldin B, Shaaban AA. Radical cystectomy and urinary diversion in women: impact on sexual function. Scandinavian journal of urology and nephrology. 2011, 45(5):332-8.

[7] De Bruijn EA, Sleeboom HP, van Helsdingen PJ, van Oosterom AT, Tjaden UR, Maes RA. Pharmacodynamics and pharmacokinetics of intravesical mitomycin $\mathrm{C}$ upon different dwelling times. International journal of cancer Journal international du cancer. 1992, 51(3):359-64.

[8] Chai M, Wientjes MG, Badalament RA, Burgers JK, Au JL. Pharmacokinetics of intravesical doxorubicin in superficial bladder cancer patients. The Journal of urology. 1994, 152(2 Pt 1):374-8.

[9] Song D, Wientjes MG, Au JL. Bladder tissue pharmacokinetics of intravesical taxol. Cancer chemotherapy and pharmacology. 1997, 40(4):285-92.

[10] Sultana S, Khan MR, Kumar M, Kumar S, Ali M. Nanoparticles-mediated drug delivery approaches for cancer targeting: a review. Journal of drug targeting. 2012.

[11] Huang PI, Lo WL, Cherng JY, Chien Y, Chiou GY, Chiou SH. Non-viral delivery of RNA interference targeting cancer cells in cancer gene therapy. Current gene therapy. 2012, 12(4):275-84.

[12] Gupta M, Agrawal GP, Vyas SP. Polymeric nanomedicines as promising vehicle for solid tumor therapy and targeting. Current molecular medicine. 2012.

[13] GuhaSarkar S, Banerjee R. Intravesical drug delivery: Challenges, current status, opportunities and novel strategies. Journal of controlled release: official journal of the Controlled Release Society. 2010, 148(2):147-59.

[14] Tyagi P, Wu PC, Chancellor M, Yoshimura N, Huang L. Recent advances in intravesical drug/gene delivery. Molecular pharmaceutics. 2006, 3(4):369-79.

[15] Lewis SA. Everything you wanted to know about the bladder epithelium but were afraid to ask. American journal of physiology Renal physiology. 2000, 278(6):F867-74.

[16] Richter WR, Moize SM. Electron Microscopic Observations on the Collapsed and Distended Mammalian Urinary Bladder (Transitional Epithelium). Journal of ultrastructure research. 1963, 39:1-9.

[17] Martin BF. Cell replacement and differentiation in transitional epithelium: a histological and autoradiographic study of the guinea-pig bladder and ureter. Journal of anatomy. 1972, 112(Pt 3):433-55.

[18] Wu XR, Lin JH, Walz T, Haner M, Yu J, Aebi U, Sun TT. Mammalian uroplakins. A group of highly conserved urothelial differentiation-related membrane proteins. The Journal of biological chemistry. 1994, 269(18):13716-24.

[19] Hicks RM. The mammalian urinary bladder: an accommodating organ. Biological reviews of the Cambridge Philosophical Society. 1975, 50(2):215-46. 
[20] Yu J, Lin JH, Wu XR, Sun TT. Uroplakins Ia and Ib, two major differentiation products of bladder epithelium, belong to a family of four transmembrane domain (4TM) proteins. The Journal of cell biology. 1994, 125(1):171-82.

[21] Kong XT, Deng FM, Hu P, Liang FX, Zhou G, Auerbach AB, Genieser N, Nelson PK, Robbins ES, Shapiro E, Kachar B, Sun TT. Roles of uroplakins in plaque formation, umbrella cell enlargement, and urinary tract diseases. The Journal of cell biology. 2004, 167(6):1195-204.

[22] Poggi MM, Johnstone PA, Conner RJ. Glycosaminoglycan content of human bladders. a method of analysis using cold-cup biopsies. Urologic oncology. 2000, 5(5):234-7.

[23] Baris D, Karagas MR, Verrill C, Johnson A, Andrew AS, Marsit CJ, Schwenn M, Colt JS, Cherala S, Samanic C, Waddell R, Cantor KP, Schned A, Rothman N, Lubin J, Fraumeni JF, Jr., Hoover RN, Kelsey KT, Silverman DT. A case-control study of smoking and bladder cancer risk: emergent patterns over time. J Natl Cancer Inst. 2009, 101(22):1553-61.

[24] Zeegers MP, Tan FE, Dorant E, van Den Brandt PA. The impact of characteristics of cigarette smoking on urinary tract cancer risk: a meta-analysis of epidemiologic studies. Cancer. 2000, 89(3):630-9.

[25] Morgan TM, Keegan KA, Clark PE. Bladder cancer. Curr Opin Oncol. 2011, 23(3):275-82.

[26] Reulen RC, Kellen E, Buntinx F, Brinkman M, Zeegers MP. A meta-analysis on the association between bladder cancer and occupation. Scand J Urol Nephrol Suppl. 2008, (218):64-78.

[27] Balbi JC, Larrinaga MT, De Stefani E, Mendilaharsu M, Ronco AL, Boffetta P, Brennan P. Foods and risk of bladder cancer: a case-control study in Uruguay. Eur J Cancer Prev. 2001, 10(5):453-8.

[28] Bade JJ, Laseur M, Nieuwenburg A, van der Weele LT, Mensink HJ. A placebo-controlled study of intravesical pentosanpolysulphate for the treatment of interstitial cystitis. British journal of urology. 1997, 79(2):168-71.

[29] Barbalias GA, Liatsikos EN, Athanasopoulos A, Nikiforidis G. Interstitial cystitis: bladder training with intravesical oxybutynin. The Journal of urology. 2000, 163(6):1818-22.

[30] Nickel JC. Interstitial cystitis: a chronic pelvic pain syndrome. The Medical clinics of North America. 2004, 88(2):467-81, xii.

[31] Warren JW, Brown J, Tracy JK, Langenberg P, Wesselmann U, Greenberg P. Evidence-based criteria for pain of interstitial cystitis/painful bladder syndrome in women. Urology. 2008, 71(3):444-8.

[32] Matsuoka PK, Haddad JM, Pacetta AM, Baracat EC. Intravesical treatment of painful bladder syndrome: a systematic review and meta-analysis. International urogynecology journal. 2012.

[33] Andersson KE. Treatment of the overactive bladder: possible central nervous system drug targets. Urology. 2002, 59 (5 Suppl 1):18-24.

[34] Jasmin L, Janni G, Manz HJ, Rabkin SD. Activation of CNS circuits producing a neurogenic cystitis: evidence for centrally induced peripheral inflammation. The Journal of neuroscience : the official journal of the Society for Neuroscience. 1998, 18(23):10016-29.

[35] Marchand JE, Sant GR, Kream RM. Increased expression of substance P receptor-encoding mRNA in bladder biopsies from patients with interstitial cystitis. British journal of urology. 1998, 81(2):224-8.

[36] Fowler CJ. Bladder afferents and their role in the overactive bladder. Urology. 2002, 59(5 Suppl 1):3742.

[37] Wein AJ, Hanno PM. Targets for therapy of the painful bladder. Urology. 2002, 59(5 Suppl 1):68-73.

[38] Chen TY, Corcos J, Camel M, Ponsot Y, Tu le M. Prospective, randomized, double-blind study of safety and tolerability of intravesical resiniferatoxin (RTX) in interstitial cystitis (IC). International urogynecology journal and pelvic floor dysfunction. 2005, 16(4):293-7.

[39] Chancellor MB, Yoshimura N. Treatment of interstitial cystitis. Urology. 2004, 63(3 Suppl 1):85-92.

[40] Rosamilia A. Painful bladder syndrome/interstitial cystitis. Best practice \& research Clinical obstetrics \& gynaecology. 2005, 19(6):843-59.

[41] Parsons JK, Parsons CL. The historical origins of interstitial cystitis. The Journal of urology. 2004, 171(1):20-2.

[42] Smaldone MC, Vodovotz Y, Tyagi V, Barclay D, Philips BJ, Yoshimura N, Chancellor MB, Tyagi P. Multiplex analysis of urinary cytokine levels in rat model of cyclophosphamide-induced cystitis. Urology. 2009, 73(2):421-6. 
[43] Tyagi P, Tyagi V, Yoshimura N, Witteemer E, Barclay D, Loughran PA, Zamora R, Vodovotz Y. Gender-based reciprocal expression of transforming growth factor-beta1 and the inducible nitric oxide synthase in a rat model of cyclophosphamide-induced cystitis. J Inflamm (Lond). 2009, 6:23.

[44] Bangham AD. A correlation between surface charge and coagulant action of phospholipids. Nature. 1961, 192:1197-8.

[45] Johnson JW, Nayar R, Killion JJ, von Eschenbach AC, Fidler IJ. Binding of liposomes to human bladder tumor epithelial cell lines: implications for an intravesical drug delivery system for the treatment of bladder cancer. Selective cancer therapeutics. 1989, 5(4):147-55.

[46] Wu XR. Urothelial tumorigenesis: a tale of divergent pathways. Nature reviews Cancer. 2005, 5(9):713-25.

[47] Barr FA, Sillje HH, Nigg EA. Polo-like kinases and the orchestration of cell division. Nature reviews Molecular cell biology. 2004, 5(6):429-40.

[48] Holtrich U, Wolf G, Brauninger A, Karn T, Bohme B, Rubsamen-Waigmann H, Strebhardt K. Induction and down-regulation of PLK, a human serine/threonine kinase expressed in proliferating cells and tumors. Proceedings of the National Academy of Sciences of the United States of America. 1994, 91(5):1736-40.

[49] Wolf G, Elez R, Doermer A, Holtrich U, Ackermann H, Stutte HJ, Altmannsberger HM, RubsamenWaigmann H, Strebhardt K. Prognostic significance of polo-like kinase (PLK) expression in non-small cell lung cancer. Oncogene. 1997, 14(5):543-9.

[50] Knecht R, Elez R, Oechler M, Solbach C, von Ilberg C, Strebhardt K. Prognostic significance of pololike kinase (PLK) expression in squamous cell carcinomas of the head and neck. Cancer research. 1999, 59(12):2794-7.

[51] Strebhardt K, Kneisel L, Linhart C, Bernd A, Kaufmann R. Prognostic value of pololike kinase expression in melanomas. JAMA : the journal of the American Medical Association. 2000, 283(4):479-80.

[52] Nogawa M, Yuasa T, Kimura S, Tanaka M, Kuroda J, Sato K, Yokota A, Segawa H, Toda Y, Kageyama S, Yoshiki T, Okada Y, Maekawa T. Intravesical administration of small interfering RNA targeting PLK-1 successfully prevents the growth of bladder cancer. The Journal of clinical investigation. 2005, 115(4):978-85.

[53] Seth S, Matsui Y, Fosnaugh K, Liu Y, Vaish N, Adami R, Harvie P, Johns R, Severson G, Brown T, Takagi A, Bell S, Chen Y, Chen F, Zhu T, Fam R, Maciagiewicz I, Kwang E, McCutcheon M, Farber K, Charmley P, Houston ME, Jr., So A, Templin MV, Polisky B. RNAi-based therapeutics targeting survivin and PLK1 for treatment of bladder cancer. Molecular therapy : the journal of the American Society of Gene Therapy. 2011, 19(5):928-35.

[54] Arum CJ, Kodama Y, Rolim N, Wideroe M, Anderssen E, Viset T, Otterlei M, Lundgren S, Chen D, Zhao CM. A rat model of intravesical delivery of small interfering RNA for studying urinary carcinoma. World journal of urology. 2010, 28(4):479-85.

[55] Killion JJ, Fan D, Bucana CD, Frangos DN, Price JE, Fidler IJ. Augmentation of antiproliferative activity of interferon alfa against human bladder tumor cell lines by encapsulation of interferon alfa within liposomes. Journal of the National Cancer Institute. 1989, 81(18):1387-92.

[56] Frangos DN, Killion JJ, Fan D, Fishbeck R, von Eschenbach AC, Fidler IJ. The development of liposomes containing interferon alpha for the intravesical therapy of human superficial bladder cancer. The Journal of urology. 1990, 143(6):1252-6.

[57] Dinney CP, Tanguay S, Bucana CD, Eve BY, Fidler IJ. Intravesical liposomal muramyl tripeptide phosphatidylethanolamine treatment of human bladder carcinoma growing in nude mice. Journal of interferon \& cytokine research: the official journal of the International Society for Interferon and Cytokine Research. 1995, 15(6):585-92.

[58] Connor J, Bannerji R, Saito S, Heston W, Fair W, Gilboa E. Regression of bladder tumors in mice treated with interleukin 2 gene-modified tumor cells. The Journal of experimental medicine. 1993, 177(4):1127-34. 
[59] Porgador A, Gansbacher B, Bannerji R, Tzehoval E, Gilboa E, Feldman M, Eisenbach L. Antimetastatic vaccination of tumor-bearing mice with IL-2-gene-inserted tumor cells. International journal of cancer Journal international du cancer. 1993, 53(3):471-7.

[60] Golumbek PT, Lazenby AJ, Levitsky HI, Jaffee LM, Karasuyama H, Baker M, Pardoll DM. Treatment of established renal cancer by tumor cells engineered to secrete interleukin-4. Science. 1991, 254(5032):713-6.

[61] Brunda MJ, Luistro L, Warrier RR, Wright RB, Hubbard BR, Murphy M, Wolf SF, Gately MK. Antitumor and antimetastatic activity of interleukin 12 against murine tumors. The Journal of experimental medicine. 1993, 178(4):1223-30.

[62] Porgador A, Bannerji R, Watanabe Y, Feldman M, Gilboa E, Eisenbach L. Antimetastatic vaccination of tumor-bearing mice with two types of IFN-gamma gene-inserted tumor cells. J Immunol. 1993, 150(4):1458-70.

[63] Dranoff G, Jaffee E, Lazenby A, Golumbek P, Levitsky H, Brose K, Jackson V, Hamada H, Pardoll D, Mulligan RC. Vaccination with irradiated tumor cells engineered to secrete murine granulocytemacrophage colony-stimulating factor stimulates potent, specific, and long-lasting anti-tumor immunity. Proceedings of the National Academy of Sciences of the United States of America. 1993, 90(8):3539-43.

[64] Horiguchi Y, Larchian WA, Kaplinsky R, Fair WR, Heston WD. Intravesical liposome-mediated interleukin-2 gene therapy in orthotopic murine bladder cancer model. Gene therapy. 2000, 7(10):844-51.

[65] Seymour GJ, Walsh MD, Lavin MF, Strutton G, Gardiner RA. Transferrin receptor expression by human bladder transitional cell carcinomas. Urological research. 1987, 15(6):341-4.

[66] Derycke AS, Kamuhabwa A, Gijsens A, Roskams T, De Vos D, Kasran A, Huwyler J, Missiaen L, de Witte PA. Transferrin-conjugated liposome targeting of photosensitizer AlPcS4 to rat bladder carcinoma cells. Journal of the National Cancer Institute. 2004, 96(21):1620-30.

[67] Fraser MO, Chuang YC, Tyagi P, Yokoyama T, Yoshimura N, Huang L, De Groat WC, Chancellor MB. Intravesical liposome administration - a novel treatment for hyperactive bladder in the rat. Urology. 2003, 61(3):656-63.

[68] Tyagi P, Chancellor M, Yoshimura N, Huang L. Activity of different phospholipids in attenuating hyperactivity in bladder irritation. BJU international. 2008, 101(5):627-32.

[69] Chuang YC, Tyagi P, Huang CC, Yoshimura N, Wu M, Kaufman J, Chancellor MB. Urodynamic and immunohistochemical evaluation of intravesical botulinum toxin A delivery using liposomes. The Journal of urology. 2009, 182(2):786-92.

[70] Chuang YC, Tyagi P, Huang HY, Yoshimura N, Wu M, Kaufman J, Chancellor MB. Intravesical immune suppression by liposomal tacrolimus in cyclophosphamide-induced inflammatory cystitis. Neurourology and urodynamics. 2011, 30(3):421-7.

[71] Chuang YC, Lee WC, Chiang PH. Intravesical liposome versus oral pentosan polysulfate for interstitial cystitis/painful bladder syndrome. The Journal of urology. 2009, 182(4):1393-400.

[72] Lee WC, Chuang YC, Chiang PH. Safety and dose flexibility clinical evaluation of intravesical liposome in patients with interstitial cystitis or painful bladder syndrome. The Kaohsiung journal of medical sciences. 2011, 27(10):437-40.

[73] Weber C, Coester C, Kreuter J, Langer K. Desolvation process and surface characterisation of protein nanoparticles. International journal of pharmaceutics. 2000, 194(1):91-102.

[74] Bae S, Ma K, Kim TH, Lee ES, Oh KT, Park ES, Lee KC, Youn YS. Doxorubicin-loaded human serum albumin nanoparticles surface-modified with TNF-related apoptosis-inducing ligand and transferrin for targeting multiple tumor types. Biomaterials. 2012, 33(5):1536-46.

[75] Elsadek B, Kratz F. Impact of albumin on drug delivery - New applications on the horizon. Journal of controlled release : official journal of the Controlled Release Society. 2012, 157(1):4-28.

[76] McKiernan JM, Barlow LJ, Laudano MA, Mann MJ, Petrylak DP, Benson MC. A phase I trial of intravesical nanoparticle albumin-bound paclitaxel in the treatment of bacillus Calmette-Guerin refractory nonmuscle invasive bladder cancer. The Journal of urology. 2011, 186(2):448-51. 
[77] Lu Z, Yeh TK, Tsai M, Au JL, Wientjes MG. Paclitaxel-loaded gelatin nanoparticles for intravesical bladder cancer therapy. Clinical cancer research : an official journal of the American Association for Cancer Research. 2004, 10(22):7677-84.

[78] Morachis JM, Mahmoud EA, Almutairi A. Physical and Chemical Strategies for Therapeutic Delivery by Using Polymeric Nanoparticles. Pharmacological reviews. 2012.

[79] Kumari A, Yadav SK, Yadav SC. Biodegradable polymeric nanoparticles based drug delivery systems. Colloids and surfaces B, Biointerfaces. 2010, 75(1):1-18.

[80] Di Martino A, Sittinger M, Risbud MV. Chitosan: a versatile biopolymer for orthopaedic tissueengineering. Biomaterials. 2005, 26(30):5983-90.

[81] Kumar MN, Muzzarelli RA, Muzzarelli C, Sashiwa H, Domb AJ. Chitosan chemistry and pharmaceutical perspectives. Chemical reviews. 2004, 104(12):6017-84.

[82] Read RC, Naylor SC, Potter CW, Bond J, Jabbal-Gill I, Fisher A, Illum L, Jennings R. Effective nasal influenza vaccine delivery using chitosan. Vaccine. 2005, 23(35):4367-74.

[83] McNeela EA, Jabbal-Gill I, Illum L, Pizza M, Rappuoli R, Podda A, Lewis DJ, Mills KH. Intranasal immunization with genetically detoxified diphtheria toxin induces $\mathrm{T}$ cell responses in humans: enhancement of Th2 responses and toxin-neutralizing antibodies by formulation with chitosan. Vaccine. 2004, 22(8):909-14.

[84] Zaharoff DA, Hoffman BS, Hooper HB, Benjamin CJ, Jr., Khurana KK, Hance KW, Rogers CJ, Pinto PA, Schlom J, Greiner JW. Intravesical immunotherapy of superficial bladder cancer with chitosan/interleukin-12. Cancer research. 2009, 69(15):6192-9.

[85] Dodane V, Amin Khan M, Merwin JR. Effect of chitosan on epithelial permeability and structure. International journal of pharmaceutics. 1999, 182(1):21-32.

[86] Ghosn B, van de Ven AL, Tam J, Gillenwater A, Sokolov KV, Richards-Kortum R, Roy K. Efficient mucosal delivery of optical contrast agents using imidazole-modified chitosan. Journal of biomedical optics. 2010, 15(1):015003.

[87] Bilensoy E, Sarisozen C, Esendagli G, Dogan AL, Aktas Y, Sen M, Mungan NA. Intravesical cationic nanoparticles of chitosan and polycaprolactone for the delivery of Mitomycin $\mathrm{C}$ to bladder tumors. International journal of pharmaceutics. 2009, 371(1-2):170-6.

[88] Wissing SA, Kayser O, Muller RH. Solid lipid nanoparticles for parenteral drug delivery. Advanced drug delivery reviews. 2004, 56(9):1257-72.

[89] Wang JX, Sun X, Zhang ZR. Enhanced brain targeting by synthesis of 3',5'-dioctanoyl-5-fluoro-2'deoxyuridine and incorporation into solid lipid nanoparticles. European journal of pharmaceutics and biopharmaceutics : official journal of Arbeitsgemeinschaft fur Pharmazeutische Verfahrenstechnik eV. 2002, 54(3):285-90.

[90] Wong HL, Bendayan R, Rauth AM, Wu XY. Development of solid lipid nanoparticles containing ionically complexed chemotherapeutic drugs and chemosensitizers. Journal of pharmaceutical sciences. 2004, 93(8):1993-2008.

[91] Li Y, Taulier N, Rauth AM, Wu XY. Screening of lipid carriers and characterization of drug-polymerlipid interactions for the rational design of polymer-lipid hybrid nanoparticles (PLN). Pharmaceutical research. 2006, 23(8):1877-87.

[92] Subedi RK, Kang KW, Choi HK. Preparation and characterization of solid lipid nanoparticles loaded with doxorubicin. European journal of pharmaceutical sciences : official journal of the European Federation for Pharmaceutical Sciences. 2009, 37(3-4):508-13.

[93] Xu Z, Chen L, Gu W, Gao Y, Lin L, Zhang Z, Xi Y, Li Y. The performance of docetaxel-loaded solid lipid nanoparticles targeted to hepatocellular carcinoma. Biomaterials. 2009, 30(2):226-32.

[94] Lin X, Gao R, Zhang Y, Qi N, Zhang K, He H, Tang X. Lipid nanoparticles for chemotherapeutic applications: strategies to improve anticancer efficacy. Expert opinion on drug delivery. 2012.

[95] Muller RH, Radtke M, Wissing SA. Nanostructured lipid matrices for improved microencapsulation of drugs. International journal of pharmaceutics. 2002, 242(1-2):121-8. 
[96] Kang MR, Yang G, Place RF, Charisse K, Epstein-Barash H, Manoharan M, Li LC. Intravesical delivery of small activating RNA formulated into lipid nanoparticles inhibits orthotopic bladder tumor growth. Cancer research. 2012.

[97] Ekambaram P, Abdul HS. Formulation and evaluation of solid lipid nanoparticles of ramipril. Journal of young pharmacists : JYP. 2011, 3(3):216-20.

[98] Klostergaard J, Seeney CE. Magnetic nanovectors for drug delivery. Nanomedicine : nanotechnology, biology, and medicine. 2012.

[99] Gommersall L, Shergill IS, Ahmed HU, Hayne D, Arya M, Patel HR, Hashizume M, Gill IS. Nanotechnology and its relevance to the urologist. European urology. 2007, 52(2):368-75.

[100] Chertok B, Moffat BA, David AE, Yu F, Bergemann C, Ross BD, Yang VC. Iron oxide nanoparticles as a drug delivery vehicle for MRI monitored magnetic targeting of brain tumors. Biomaterials. 2008, 29(4):487-96.

[101] Chen CH, Yang HJ, Shun CT, Huang CY, Huang KH, Yu HJ, Pu YS. A cocktail regimen of intravesical mitomycin-C, doxorubicin, and cisplatin (MDP) for non-muscle-invasive bladder cancer. Urologic oncology. 2010.

[102] Goodwin SC, Bittner CA, Peterson CL, Wong G. Single-dose toxicity study of hepatic intra-arterial infusion of doxorubicin coupled to a novel magnetically targeted drug carrier. Toxicological sciences : an official journal of the Society of Toxicology. 2001, 60(1):177-83.

[103] Leakakos T, Ji C, Lawson G, Peterson C, Goodwin S. Intravesical administration of doxorubicin to swine bladder using magnetically targeted carriers. Cancer chemotherapy and pharmacology. 2003, 51(6):445-50.

[104] Shen Z, Shen T, Wientjes MG, O'Donnell MA, Au JL. Intravesical treatments of bladder cancer: review. Pharmaceutical research. 2008, 25(7):1500-10.

[105] Zuiverloon TC, Nieuweboer AJ, Vekony H, Kirkels WJ, Bangma CH, Zwarthoff EC. Markers predicting response to bacillus Calmette-Guerin immunotherapy in high-risk bladder cancer patients: a systematic review. European urology. 2012, 61(1):128-45. 


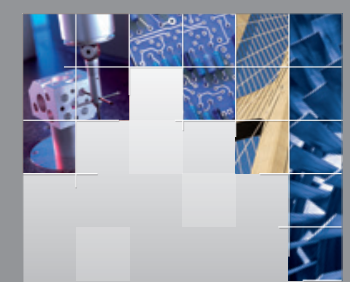

\section{Enfincering}
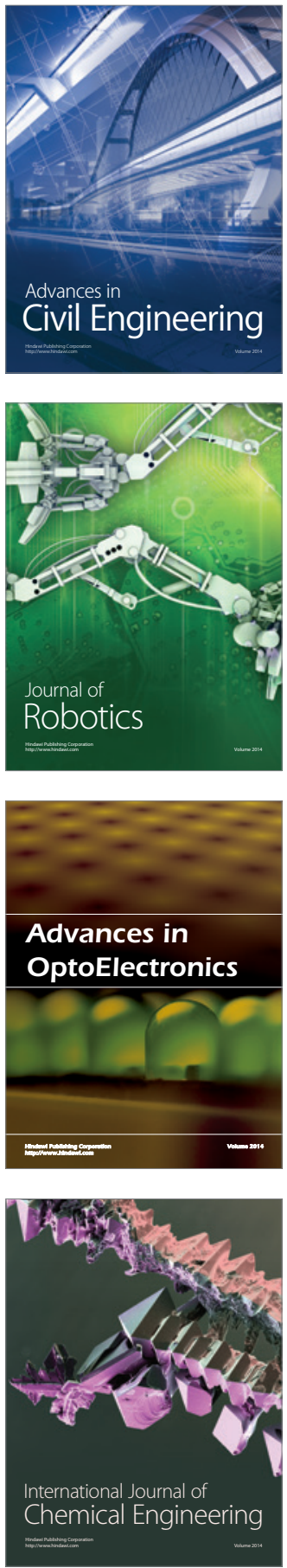

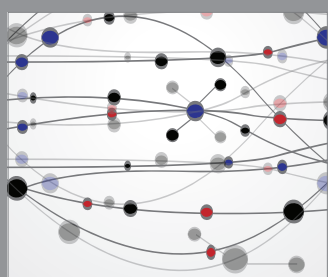

The Scientific World Journal

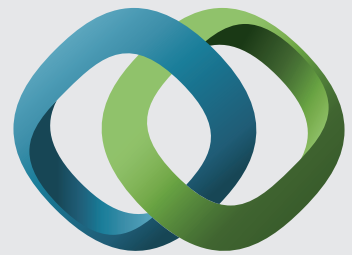

\section{Hindawi}

Submit your manuscripts at

http://www.hindawi.com
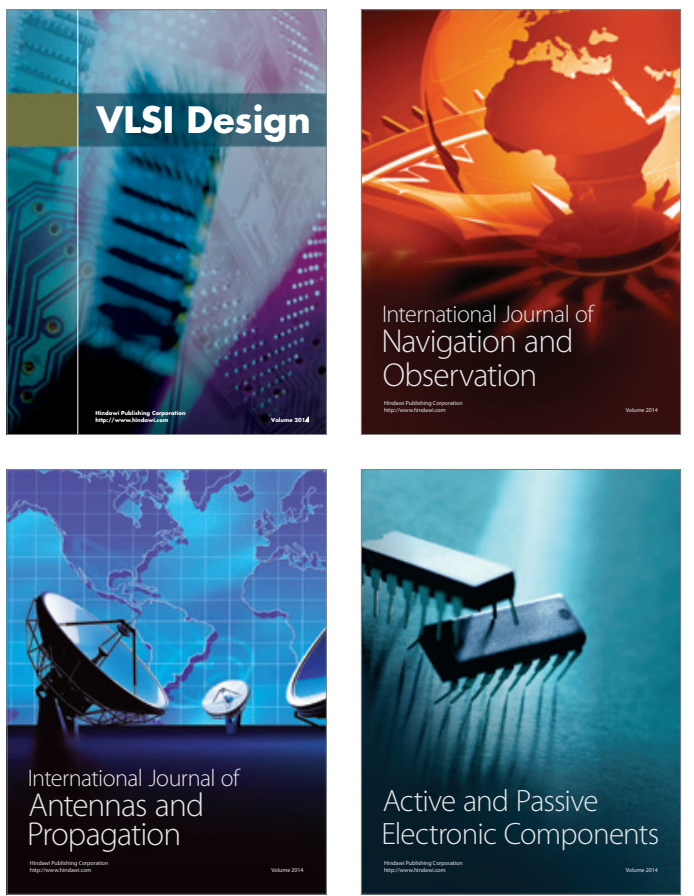
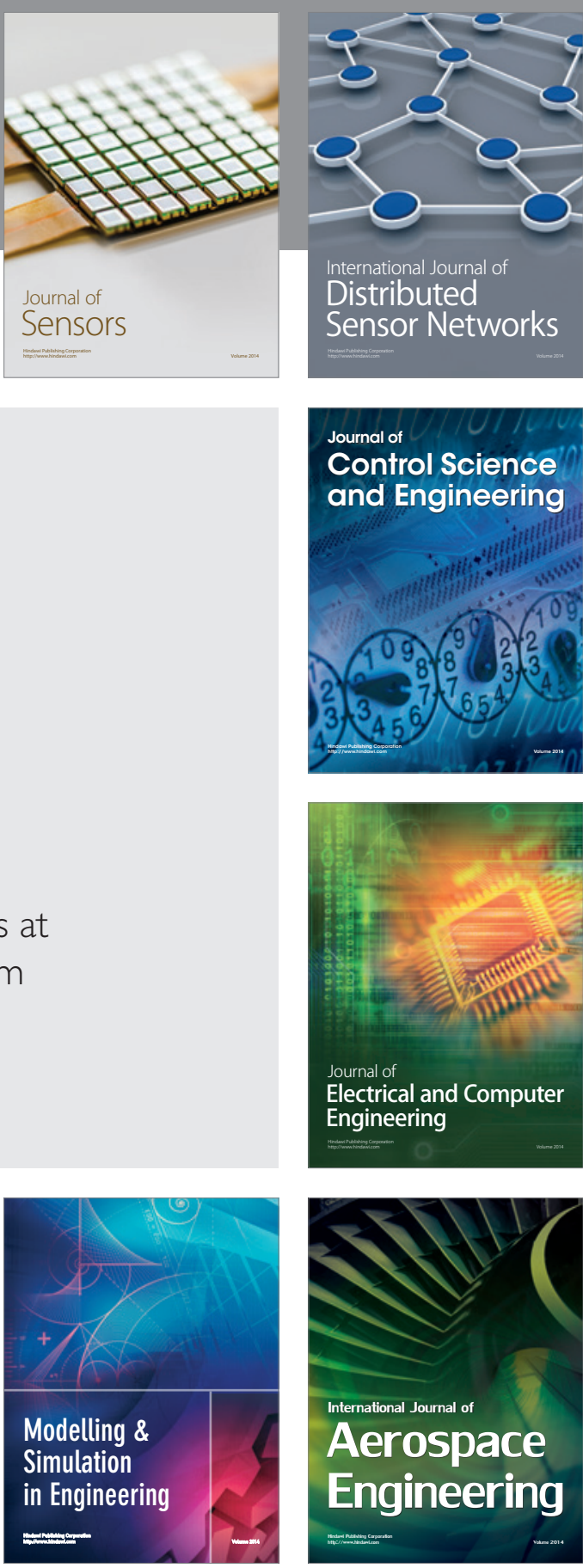

International Journal of

Distributed

Sensor Networks

Journal of

Control Science

and Engineering
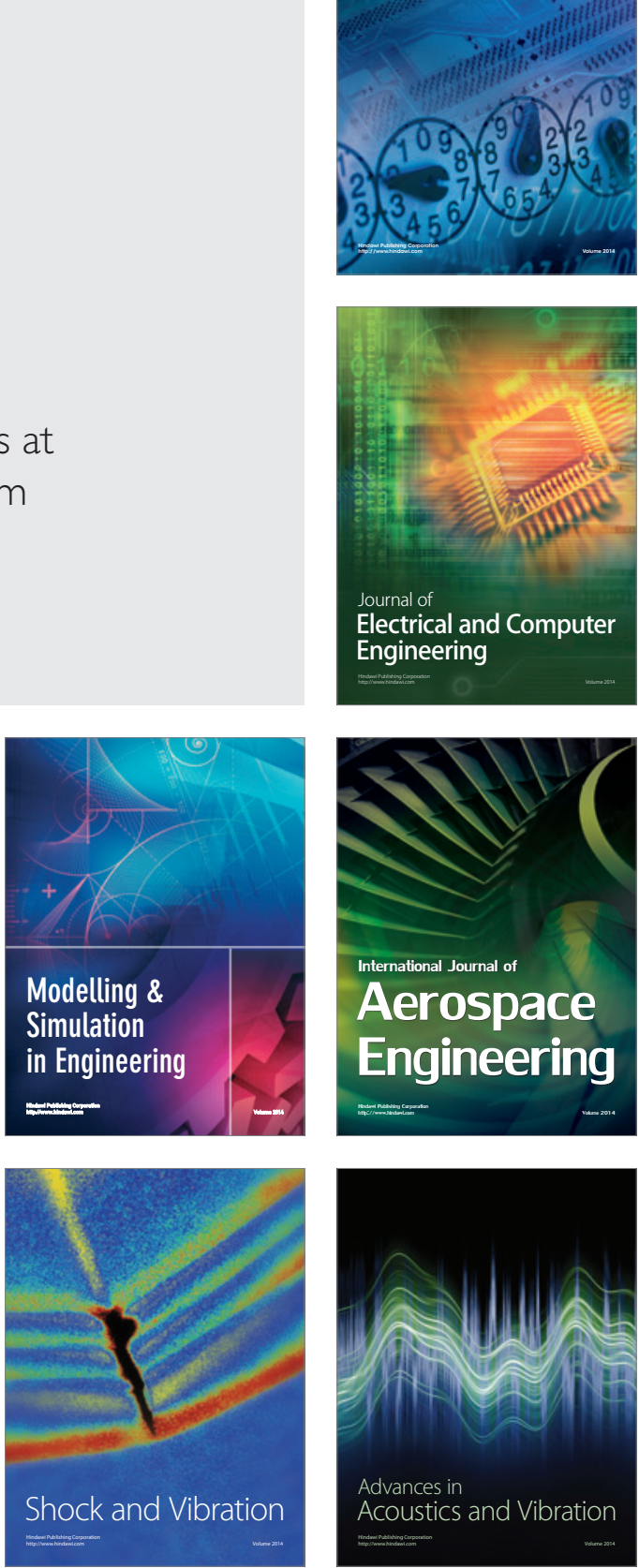